\title{
El confinamiento por Covid-19: repercusión en el desarrollo socioemocional y rendimiento académico en estudiantes de $\mathbf{7}^{\circ}$ curso del Colegio Menor
}

\author{
Lic. Ana Iris Pérez Gallardo \\ anitapg96@gmail.com \\ Maestría en Psicología con mención en neuropsicología del aprendizaje \\ Universidad Estatal de Milagro \\ Dr. Ernesto Tabares Cruz \\ ernestotabares70@yahoo.es \\ Maestría en Psicología con mención en neuropsicología del aprendizaje \\ Universidad Estatal de Milagro
}

\section{RESUMEN}

La pandemia ocasionada por el virus SARS-COV 2, ha generado importantes transformaciones en todas las esferas de la vida social que han impactado significativamente en la vida de los seres humanos. El confinamiento generado trajo consigo que el escenario educacional se trasladara a los hogares y las formas tradicionales de organizar los procesos de enseñanza- aprendizaje cambiaran sustancialmente, hechos que se plantea han influido en el desarrollo socioemocional y resultados académicos de los estudiantes, razón por la cual se ha realizado este estudio de carácter descriptivo y comparativo de tiempo, cuyo objetivo fue identificar el impacto que ha tenido el confinamiento por la COVID- 19 en el desarrollo socioemocional y rendimiento académico de los estudiantes de 7mo curso de Educación Básica General (EGB) del Colegio MENOR, Campus Samborondón. Los resultados alcanzados muestran que el desarrollo socioemocional no figura como un aspecto negativo en la población estudiada, de manera general los alumnos encuestados reflejan estabilidad emocional y sus relaciones personales, pese al confinamiento, han transcurrido de manera aceptable; el rendimiento académico fue superior en comparación con el período 2019-2020, en todo ello indudablemente ha incidido la influencia del ambiente familiar y las condiciones de vida de estos estudiantes.

Palabras Clave: confinamiento; desarrollo socioemocional, rendimiento académico 


\title{
Confinement by Covid-19: impact on socio-emotional development and academic performance in students of 7th year of Colegio Menor
}

\begin{abstract}
The pandemic caused by the SARS-COV 2 virus has generated important transformations in all spheres of social life that have significantly impacted the lives of human beings. The confinement generated brought with it that the educational scenario was transferred to the homes and the traditional ways of organizing the teaching-learning processes changed substantially, facts that have influenced the socio-emotional development and academic results of the students, which is why this study of a descriptive and comparative nature of time has been carried out, whose objective was to identify the impact that the confinement by COVID-19 has had on the socio-emotional development and academic performance of the students of the 7th year of General Basic Education (EGB) at Colegio MENOR, Campus Samborondón. The results achieved show that social-emotional development does not appear as a negative aspect in our research. In general, the students surveyed reflect emotional stability and their personal relationships, despite the confinement, have passed in an acceptable way, in which undoubtedly the influence of the family environment and living conditions have influenced. Furthermore, it was also shown that the academic performance was superior compared to the period 2019-2020.
\end{abstract}

Keywords: confinement; socio-emotional development, academic performance

Artículo recibido: 02 Setiembre. 2021 Aceptado para publicación: 30 Setiembre. 2021

Correspondencia: anitapg96@gmail.com Conflictos de Interés: Ninguna que declarar 


\section{INTRODUCCIÓN}

La aparición de la COVID-19, enfermedad producida por el nuevo coronavirus SARSCOV-2 e informada por vez primera en China en diciembre de 2019, dado su alto nivel de contagio y por ende rápida expansión, se declaró por la OMS como pandemia en marzo de 2020, a partir de considerar que pandemia es la propagación mundial de una nueva enfermedad, producida por la aparición de un nuevo virus que se disemina por el mundo porque afecta a más de un continente, que la mayor parte de las personas no presentan inmunidad contra él y se produce una transmisión comunitaria, lo que conduce a un aislamiento mundial, en consecuencia y oportunamente, se convocó a tomar un conjunto de medidas encaminadas a controlar lo que se ha concebido como la más grande emergencia sanitaria en el mundo contemporáneo.

Entre las mencionadas medidas para contener la propagación del virus, se han puesto en práctica momentos que difieren entre sí no solo por los términos utilizados, sino por su contenido según plantean autores como García y Cuéllar (2020), quienes asumen la cuarentena como un momento de restricción que puede tener carácter obligatorio o voluntario y que implica la restricción del movimiento de personas que han estado bajo el riesgo de contagio y tienen la posibilidad de haberse infectado, por lo que deben mantenerse en un lugar mientras dure el período de incubación de la enfermedad hasta que pase el mismo (14 días), en tanto que dichos autores consideran que aislamiento es la separación física de las personas contagiadas de las que están sanas.

El otro concepto que se ha manejado y de hecho aplicado, es el distanciamiento social que como indican los autores antes mencionados, no es más que establecer determinada separación y preservar entre las personas los espacios físicos fijados. Por otra parte se ha puesto en práctica el confinamiento, visto este como un plan de emergencia comunitaria que conlleva a permanecer refugiadas a las personas todo el tiempo que sea posible y observando nuevas reglas que limitan el comportamiento social, implica como señalan Sánchez y Fuentes (2020) “permanecer refugiado el mayor tiempo posible bajo nuevas normas socialmente restrictivas" (p.2).

Atendiendo a estas concepciones, se ha considerado asumir en este trabajo el término confinamiento, dada su significación y atendiendo a que es lo que está sucediendo en toda la realidad ecuatoriana, como en otros países y específicamente en el contexto educacional. 
En la búsqueda bibliográfica realizada se ha puesto de manifiesto que varios autores, entre ellos García, et.al. (2020), Hincapié, et.al. (2020), CEPAL-UNESCO (2020), Heredia (2020), Sánchez (2021), Intriago y Calle (2021), entre otros, han incursionado en la problemática relacionada con el impacto que la pandemia originada por la COVID-19 ha generado en los estudiantes en áreas psico-sociales y rendimiento académico.

Señalan autores como Hincapié, et.al. (2020), Heredia (2020), que existen factores como la sensación de inmovilidad que provoca el confinamiento, la vida rutinaria, la falta de estímulos externos para lograr nuevos aprendizajes, el tiempo ante una computadora, los cambios tanto en los hábitos de sueño como en los alimenticios, que pueden incidir en el estado socioemocional y en el aumento de niveles de estrés, aburrimientos, frustración, y ansiedad que traen consigo respuestas que revelan desilusión y enfado, lo que repercute en las relaciones sociales que se desarrollan en el entorno del hogar y, por supuesto, también en el resto de las relaciones sociales, dada la falta de comunicación interpersonal, con compañeros de clase y el resto del personal de la escuela, incluyendo a los docentes. Es importante tener presente, tal como plantean autores como Cohen (2003), Heras et.al. (2016), Heredia (2020), que el desarrollo socioemocional es la facultad que tienen las personas y en este caso los niños y niñas, para entender a quienes tienen a su alrededor, dominar sus sentimientos y maneras de comportarse y establecer un adecuado ambiente de convivencia con sus compañeros y el resto de las personas con quienes comparten su diario vivir. Añaden otros autores como Berger et.al. (2020) que significa que las competencias socioafectivas deben integrarse con elementos tales como la valoración propia, establecer fuertes relaciones con otras personas y concebir de manera real y exacta el ambiente que le rodea.

En la medida en que el individuo se va desarrollando, esta capacidad también crece y aparecen nuevas habilidades que permiten enfrentar los retos que se presentan, entre ellos, fomentar mejores relaciones interpersonales, ser más responsable al tomar determinadas decisiones, ser capaz de ponerse en el lugar de otros o lo que es igual practicar la empatía. La realidad enfrentada a partir de la pandemia por Covid-19, ha generado circunstancias que como indica CEPAL-UNESCO (2020), han influido en la aparición de niveles no previstos de vulnerabilidad y con ello considerable afectación en habilidades sociales y de aprendizaje que pueden incidir negativamente en el rendimiento académico, entendido 
este como "el nivel de conocimientos demostrado en un área o materia comparado con la norma” (Torres y Rodríguez, 2006, p.262).

A estos argumentos se añade, según (Rieble-Aubourg y Viteri, 2020) que existe un acceso diferenciado a conexiones de Internet que se pone de manifiesto en recursos y estrategias distintas, realidad que impacta fundamentalmente a las capas de la población de más bajos ingresos y más vulnerables. De esto se infiere que aquellos estudiantes que presentan situaciones desventajosas desde el punto de vista económico y social, tendrán mayores dificultades para enfrentar los procesos de aprendizaje en el entorno del hogar, lo que repercutirá en su estado emocional y en consecuencia en el rendimiento académico, y por tanto ahondarán las diferencias y desniveles en este período.

La inequidad en el aprendizaje crecerá, dice el (Grupo del Banco Mundial, 2020), por cuanto aquellos estudiantes que pertenecen a familias de mayor solvencia económica y con más educación, podrán recibir mejor apoyo para enfrentar el aprendizaje desde la casa.

Otro riesgo que se corre es el aumento de la deserción escolar, porque el apego que sienten con la institución escolar aquellos estudiantes que presentan determinado nivel de vulnerabilidad, puede disminuir debido a que no cuentan directamente con el contacto de una estructura escolar y puede que tampoco con docentes que les motiven.

Desde la perspectiva pedagógica, la modalidad virtual ha traído consigo la pérdida de la presencialidad y el aumento de tensiones debido a la exposición excesiva de estudiantes y docentes y/o por inconvenientes para conservar la interacción y la mediación pedagógica (CEPAL-UNESCO, 2020).

Es importante como indicaron (Hernández-Godoy, et.al.,2018), tener presente que aquellos estudiantes que se enfrentan a la educación en línea con determinado dominio tecnológico y que han sido preparados previamente no solo desde el punto de vista técnico, sino también pedagógico, sufren menos estrés ante los sistemas de aprendizaje a distancia y su predisposición ante ella puede ser positiva. 


\section{MATERIAL Y MÉTODO}

El estudio que se realiza es de carácter descriptivo y comparativo de tiempo, por cuanto centra la atención en identificar el impacto que ha tenido el confinamiento por la COVID19 en el desarrollo socioemocional y rendimiento académico de los estudiantes de $7 \mathrm{mo}$ curso de Educación Básica General (EGB) del Colegio MENOR Campus Samborondón de la provincia de Guayas, Ecuador, y se realiza una comparación de resultados alcanzados pre y post pandemia en el aprendizaje y la posible incidencia de los cambios emocionales producidos en ellos.

Como indica Cifuentes-Faura (2020), aunque para algunos alumnos no ir a la escuela inicialmente puede ser bastante emocionante y un alivio, la falta de socialización y aprendizaje podría acabar siendo un gran problema a largo plazo y añade que la inasistencia a las escuelas producirá un aumento de las desigualdades en los resultados educativos, generándose una brecha en el aprendizaje, el que es probable se ralentice y se produzca como impacto un desgaste psicológico en los niños, fenómeno que desde el punto de vista científico resulta oportuno estudiar. Estas razones han motivado que el objetivo planteado en el presente trabajo haya estado dirigido a determinar el impacto del confinamiento generado por la COVID 19 en los procesos de socioemocionales y rendimiento académico de los estudiantes de 7mo UBG del Colegio MENOR, Campus Samborondón.

La población considerada en el estudio estuvo conformada por 100 alumnos de $7 \mathrm{mo}$ de EGB del Colegio Menor Samborondón teniendo en cuenta las características de los mismos, consideradas estas como elemento importante que contribuyó al logro del objetivo propuesto; se estudiaron 70 alumnos, los que conformaron una muestra no probabilística apoyada en la técnica de muestreo intencional o de conveniencia, se consideró que la cifra proporcionaba los sujetos necesarios para verificar los supuestos planteados, además de que todos son alumnos del mismo grado y han transitado por el año de estudio en las mismas condiciones de confinamiento y orientados por la metodología que rige la educación a distancia. El criterio de exclusión atendió a la disposición de los padres a través de la variante consentimiento informado, que por tratarse de niños y niñas se concibe como carta de asentimiento para que sus hijos fueran incluidos en el estudio. 
La edad promedio de los alumnos osciló en un rango entre 11-12 años, de los cuales el $50 \%$ pertenece a cada sexo. Son niños y niñas cuyo estatus socio-económico es alto, lo que les proporciona un buen nivel de vida ya que materialmente cuentan con todas sus necesidades cubiertas y no han tenido que enfrentar dificultades con el sustento tecnológico que exige este tipo enseñanza.

Los datos fueron obtenidos a partir de la aplicación de la encuesta como método empírico, utilizando el cuestionario WHOQOL-BREF, instrumento genérico conformado por 26 preguntas, de las cuales 24 permitieron a partir de su concepción, evaluar la calidad de vida y 2 hicieron posible evaluar satisfacción con el estado de salud en cuanto a las dimensiones relacionadas con la salud física, psicológica, relaciones sociales y ambiente que inciden en el desarrollo socio emocional. En el procedimiento para el procesamiento se tuvo en cuenta, que las puntuaciones mayores indican mayor calidad de vida y las opciones de las escalas de respuesta según el tipo Likert para comprender el nivel de satisfacción.

La evaluación del rendimiento académico se realizó aplicando la herramienta, Medida de Progreso Académico (MAP TESTS por sus siglas en inglés), prueba que permite evaluar a estudiantes desde el nivel primario hasta el secundario. Con ella se midió comprensión lectora, matemática, ciencias e idioma inglés, por tratarse de una prueba de carácter adaptativo que hizo posible analizar y comparar los resultados de los MAP TESTS en los años lectivos 2019-2020; previo a la pandemia, y 2020-2021, primer año de pandemia. Es una prueba que posibilitó apreciar la existencia o no de progresos.

Las variables determinadas en el estudio responden al papel que han desempeñado en la investigación y se consideraron como variables modificadoras del efecto dada la modificación que se puede producir en la interacción entre el confinamiento, el desarrollo socio-emocional y el rendimiento académico.

"El confinamiento es un plan de intervención comunitario que implica permanecer refugiado el mayor tiempo posible, bajo nuevas normas socialmente restrictivas" (Sánchez, A. y La Fuente, V., 2020, p.2).

El desarrollo socio-emocional, según Berger, et.al. (2014) “implica integrar competencias socioafectivas con otros aspectos como la valoración de sí mismo, el establecimiento de vínculos nutritivos con otros, y una percepción positiva del ambiente” (p.170). 
Se asume como rendimiento académico "el nivel de conocimientos demostrado en un área o materia comparado con la norma (edad y nivel académico), generalmente medido a través del promedio escolar" (Torres y Rodríguez, 2006, p.262).

Los datos obtenidos de la aplicación del instrumento WHOQOL-BREF, que posibilitó medir calidad de vida, fueron procesadas en un documento de Excel, donde se pudo analizar el bienestar emocional y la interacción de la calidad de vida de los alumnos en cuestión.

Los resultados alcanzados de la aplicación de la herramienta Map Test, fueron analizados a través del programa informático estadístico SPSS, el que permitió constatar la curva de desarrollo de las destrezas adquiridas por los alumnos antes y durante la pandemia.

Se realizó una revisión bibliográfica para precisar el marco conceptual que sirvió de sustento al artículo, utilizando diferentes fuentes de información entre ellas, artículos científicos, monografías, encuestas, encontrados en bases documentales como Scielo, Redalyc, Dialnet, Latindex.

\section{RESULTADOS Y DISCUSIÓN}

Con el objetivo de abordar el impacto del aislamiento en el aspecto emocional y calidad de vida, se utilizó la escala WHOQOL-BREF establecida por la OMS, la cual consta de 4 dominios: físico, psicológico, relaciones sociales y ambiente. Las variables de tipo ordinal (cualitativas) recopiladas en la encuesta de Google fueron procesadas en un documento de Excel, donde se pudo analizar el bienestar emocional, de interacción de la calidad de vida de los alumnos en cuestión.

\section{Los resultados alcanzados expresan que:}

El 68\% de los alumnos reconocieron tener una calidad de vida muy buena y el $82.85 \%$ se siente conforme con su salud, aceptando que están bastante satisfechos y muy satisfechos con su bienestar físico y mental. 
¿Cómo puntuaría su calidad de vida?

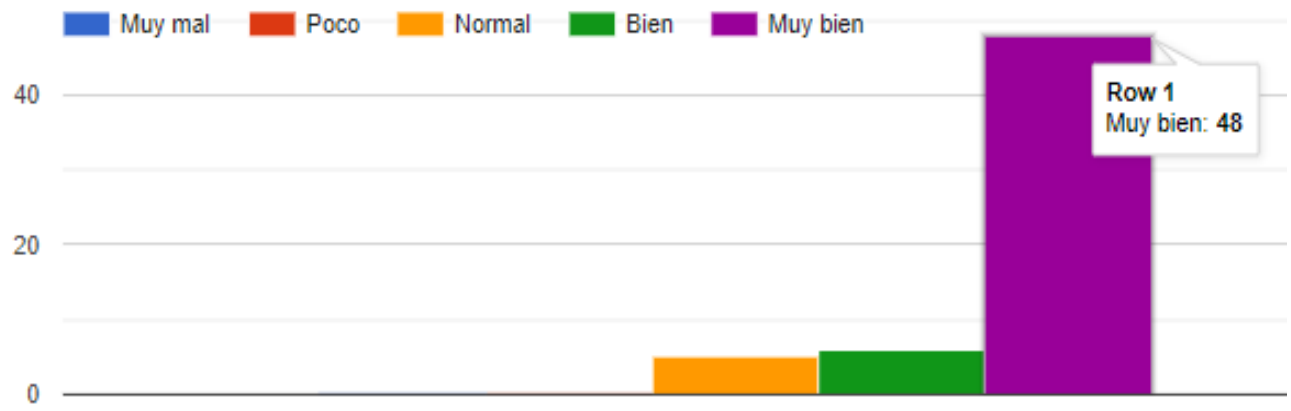

¿En qué medida siente que su vida tiene sentido?

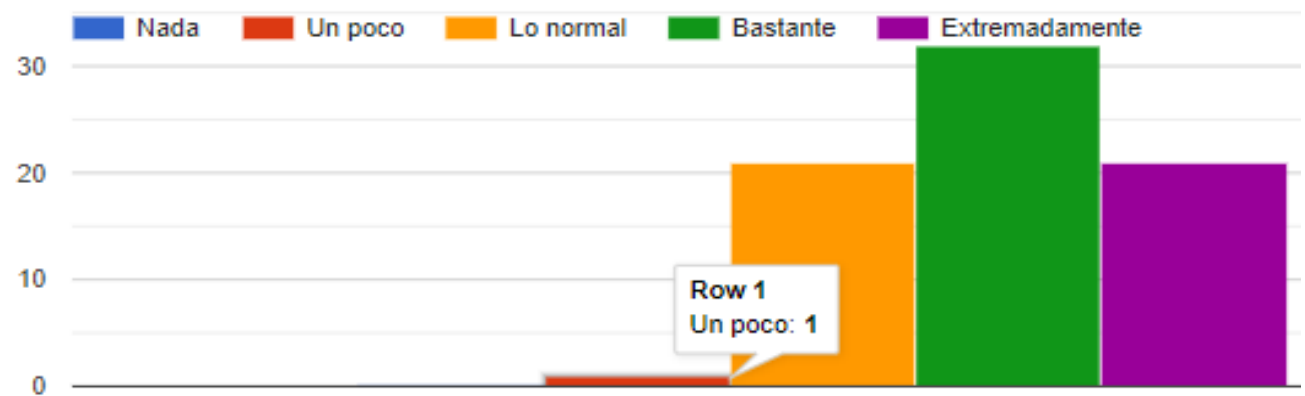

2. ¿Cuán satisfecho/a está con su salud?

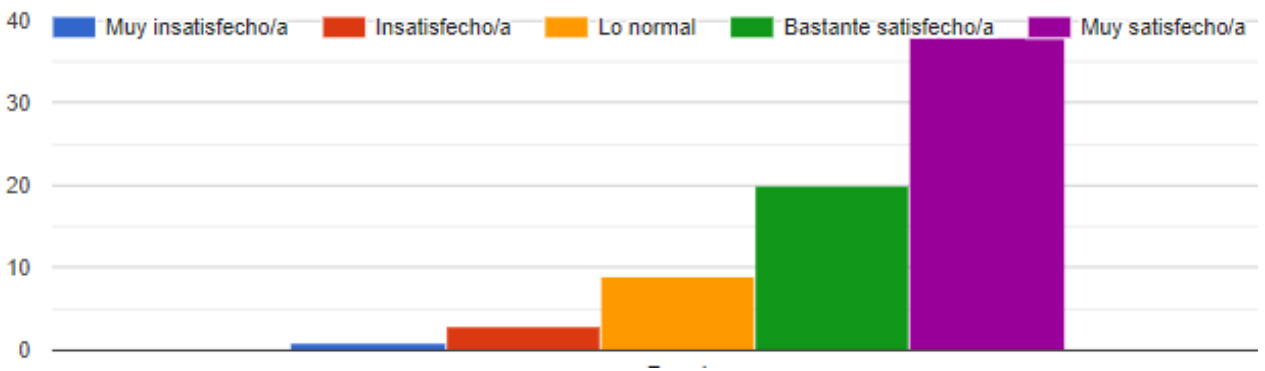

Ciencia Latina Revista Científica Multidisciplinar, Ciudad de México, México.

ISN 2707-2207 / ISSN 2707-2215 (en línea), setiembre-octubre, 2021, Volumen 5, Número 5. https://doi.org/10.37811/cl_rcm.v5i5.985 p9235 


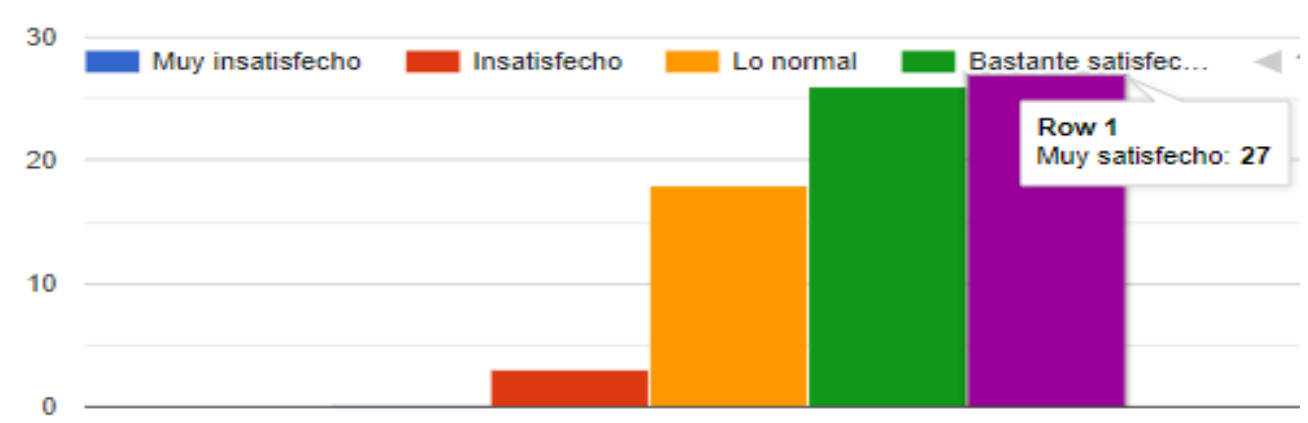

Asimismo, en cuanto al bienestar emocional y cómo disfrutan la vida, solo el 1,42\%

¿Cuánto disfruta de la vida?

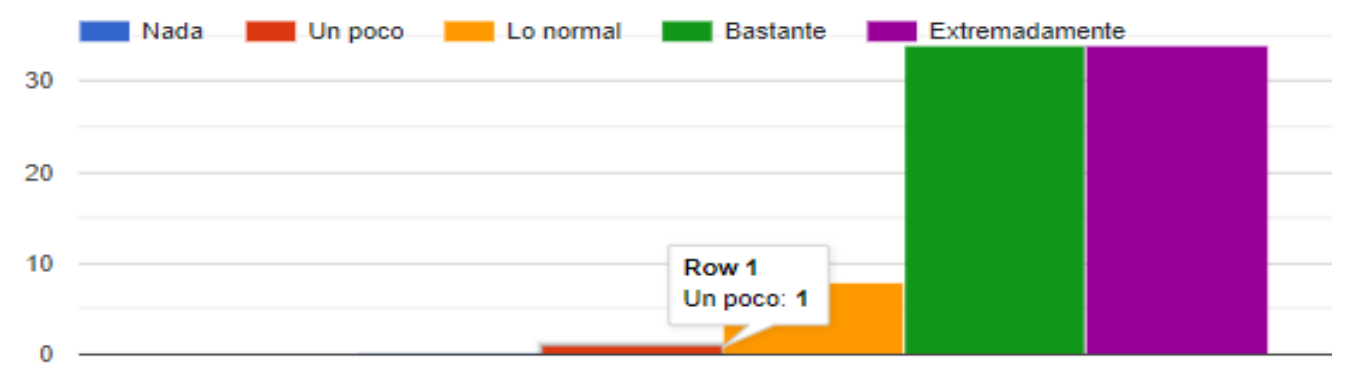

expresó una respuesta negativa, alegando que no disfrutaba de la vida. Este alumno, presentó dificultades en el examen académico, y también en la encuesta aplicada punteó bajo en otros aspectos emocionales asociados con el ambiente y las relaciones interpersonales 


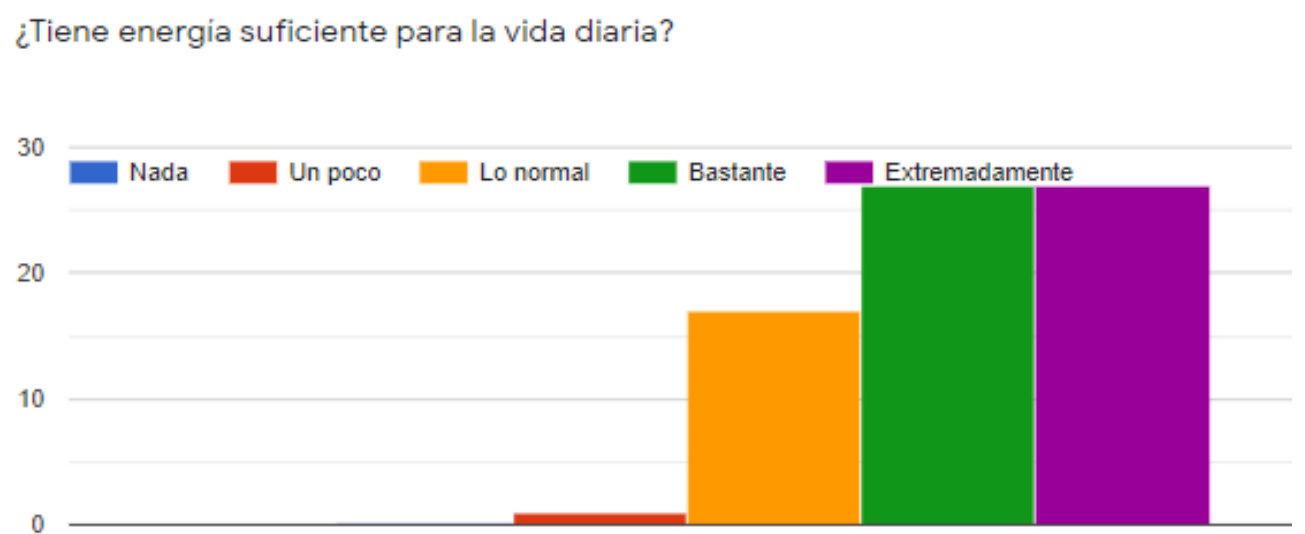

¿Cuál es su capacidad de concentración?

Los

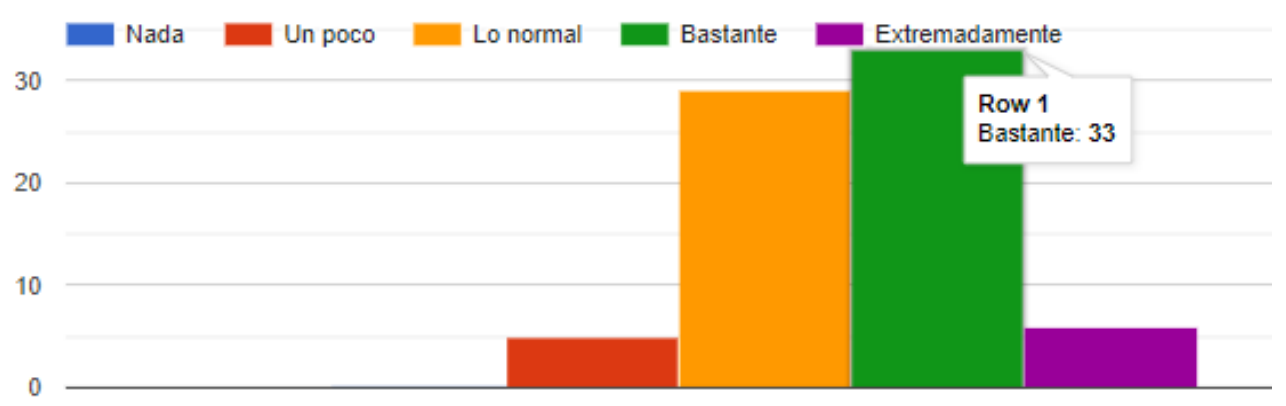

resultados anteriores comprueban los planteamientos de Berger, et.al, (2014) cuando incursionan en la problemática del desarrollo socioemocional que señalan que las competencias socioafectivas deben integrarse con elementos tales como la valoración propia, establecer fuertes relaciones con otras personas y concebir de manera real y exacta el ambiente que le rodea.

Al analizar el ambiente escolar y su capacidad de concentración durante el período de confinamiento y las clases virtuales, el $55.71 \%$ expresó tener una buena capacidad en este sentido, aspecto que influye directamente en el rendimiento académico y los resultados obtenidos en la aplicación de la herramienta MAP test para medir su avance académico.

Además, el $82.85 \%$ de los alumnos encuestados reflejaron tener buen acceso a los medios digitales y la información necesaria, no solo para los temas académicos, sino también para estar informados de la situación global a causa de la pandemia del COVID 19; y el 68.57\% expresó estar satisfecho o muy satisfecho con su capacidad de trabajo, lo que les ha permitido realizar los deberes orientados. 
¿Qué disponible tiene la información que necesita en su vida diaria?

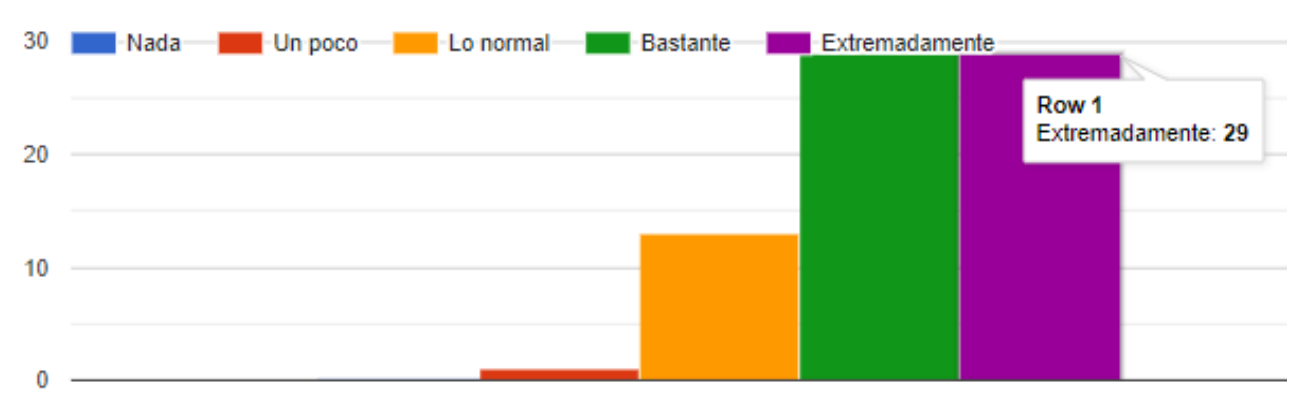

¿Cuán satisfecho/a está con su capacidad de trabajo?

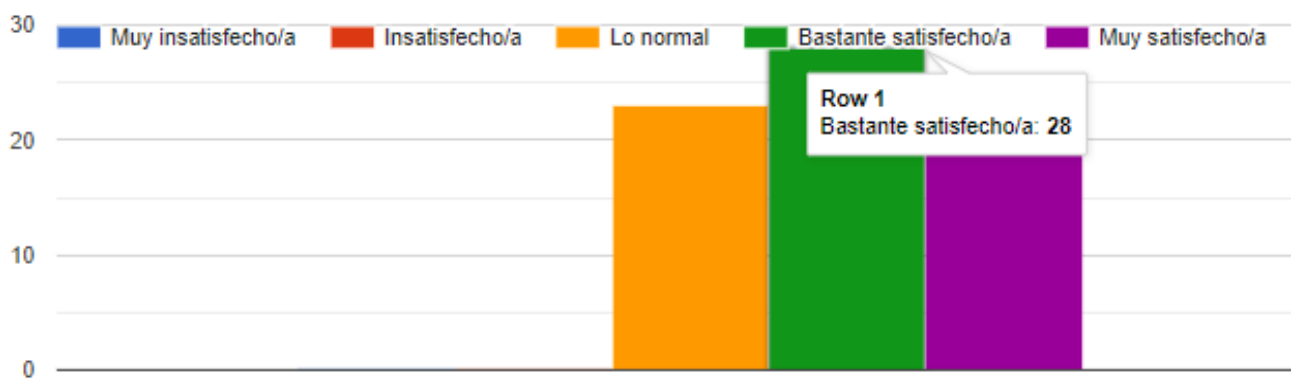

- ¿Cuán satisfecho/a está con el apoyo que obtiene de sus amigos?

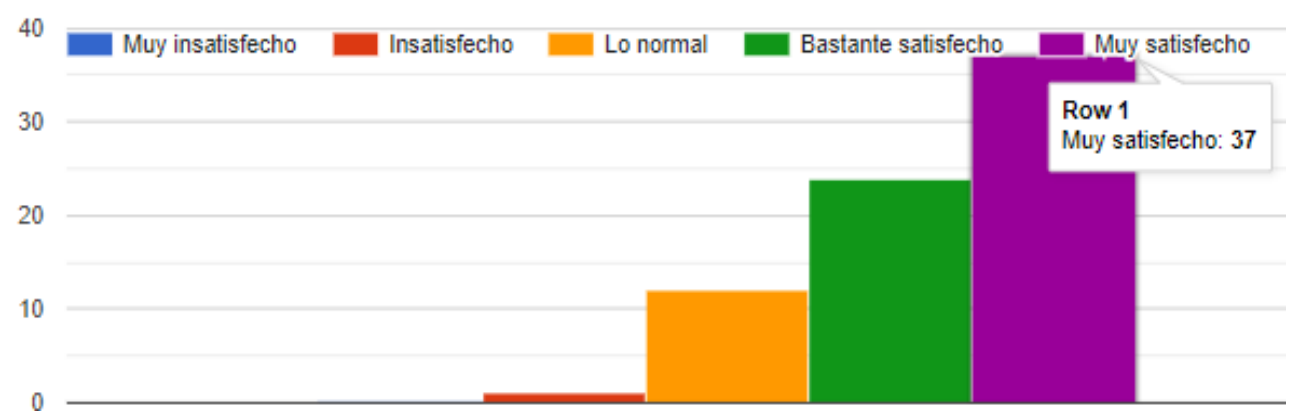

A pesar del confinamiento a que han sido sometidos los estudiantes en general, producto de la pandemia originada por la COVID-19, y el desgaste evidenciado en las altas horas de conexión virtual, así como la imposibilidad de interactuar con sus pares, lo que ha provocado un alto nivel de vulnerabilidad, y como consecuencia, una afectación en el desarrollo de competencias sociales y de aprendizaje, los estudiantes encuestados que constituyeron la muestra en esta investigación, expresaron haber logrado una comunicación adecuada con sus pares a través de las clases virtuales y los medios de redes 
sociales, siendo así que un $65.71 \%$ expresó sentirse satisfecho con las relaciones personales, no solo dentro de su núcleo familiar, sino también con el apoyo de sus amigos, el 31,44\% declaró sentir una satisfacción normal en este sentido y solo un 2.85\% expresó sentirse muy insatisfecho, coincidiendo esto con los mismos estudiantes que habían punteado bajo en su calidad de vida, y en los otros aspectos emocionales analizados anteriormente.

¿Cuán satisfechola está con sus relaciones personales?

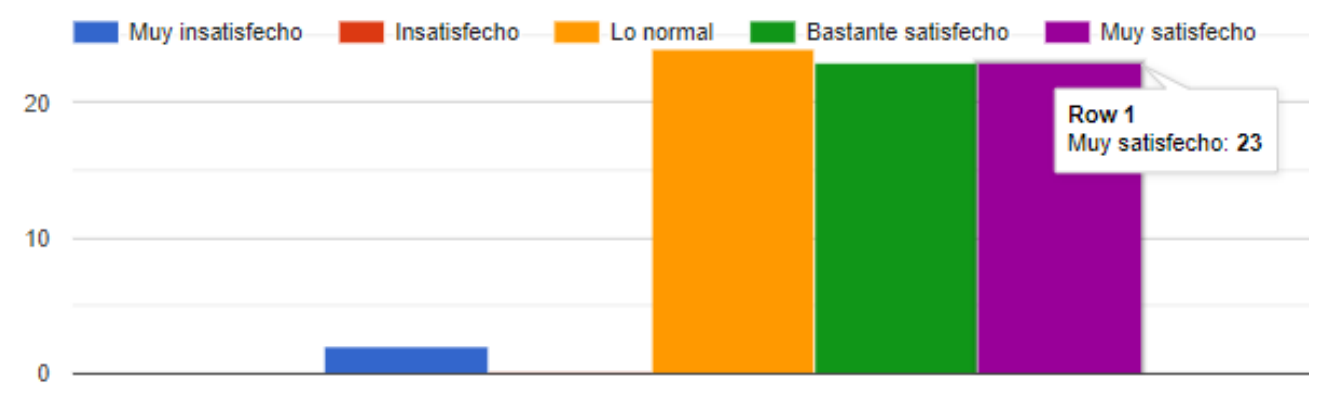

El sueño resulta de mucha significación en el proceso de aprendizaje y por tanto en el alcance de los resultados y rendimiento académico, por ser considerado como una estado fisiológico, el cual es imprescindible para la vida humana y que si bien implica una disminución de la conciencia y del estado de alerta, durante el período de sueño, afirma Bauzano (2003) que desarrolla procesos que necesitan una total imbricación de la actividad cerebral y donde varios procesos fisiológicos del organismo, sufren transformaciones. Se ha demostrado en distintas investigaciones que el sueño influye en varios procesos que se operan en el ser humano como son los estados anímicos y comportamentales, las respuestas del sistema inmune, la memoria, el aprendizaje, el metabolismo, los procesos digestivos, entre otros.

Como puede apreciarse en la gráfica siguiente, el 95,75\% de los encuestados describieron su sueño como bastante satisfactorio, y normal, en tanto que un $4,25 \%$ se siente insatisfecho o muy insatisfecho con la manera en que logra conciliar el sueño, el alto porcentaje de satisfacción nos permiten considerar que en la muestra estudiada este 
aspecto se puede interpretar como un factor positivo para el aprendizaje y el rendimiento académico.

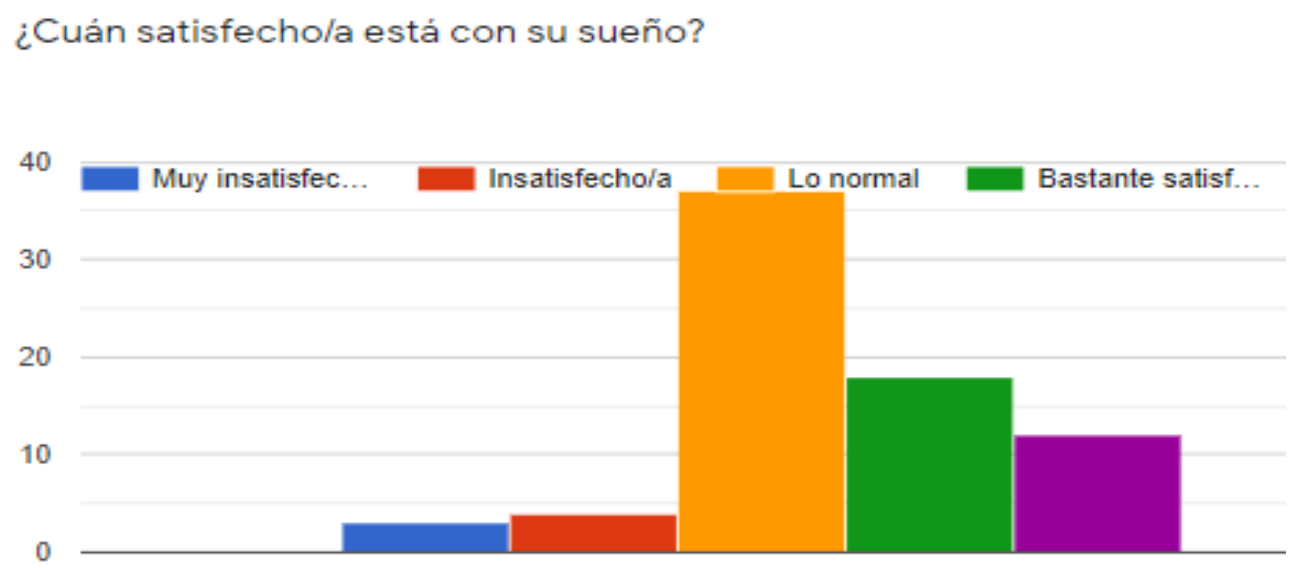

Es necesario también complementar con la seguridad que sienten los encuestados de acuerdo a su ubicación demográfica, pues de esta manera se centran en sí mismos y en su aprendizaje, sin sentirse amenazados o en peligro. El $88.57 \%$ de los estudiantes seleccionó estar bastante y muy satisfecho, no solo con su entorno y lugar donde viven, sino también con la seguridad que sienten en sus vidas y en el entorno donde se encontraban durante el período de confinamiento.

¿Cuán satisfecho/a está de las condiciones del lugar donde vive?

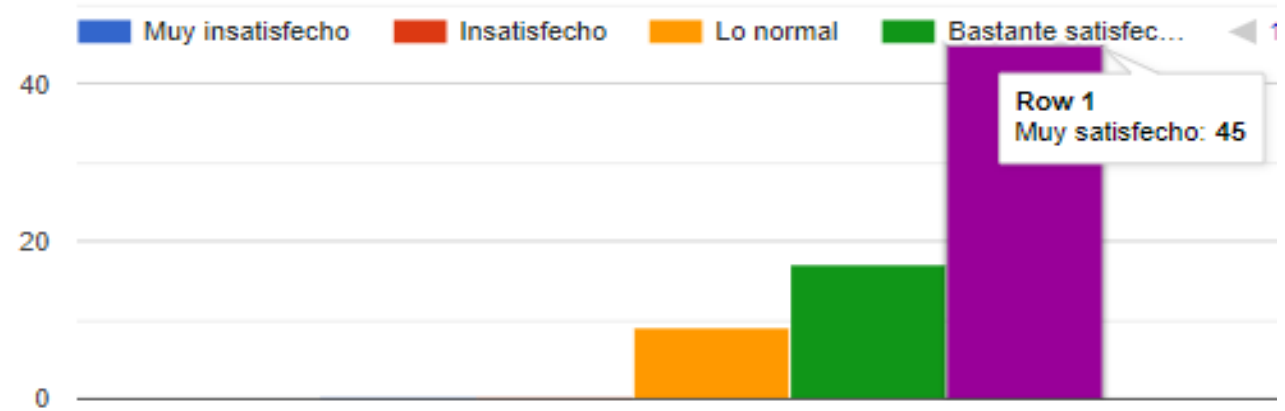




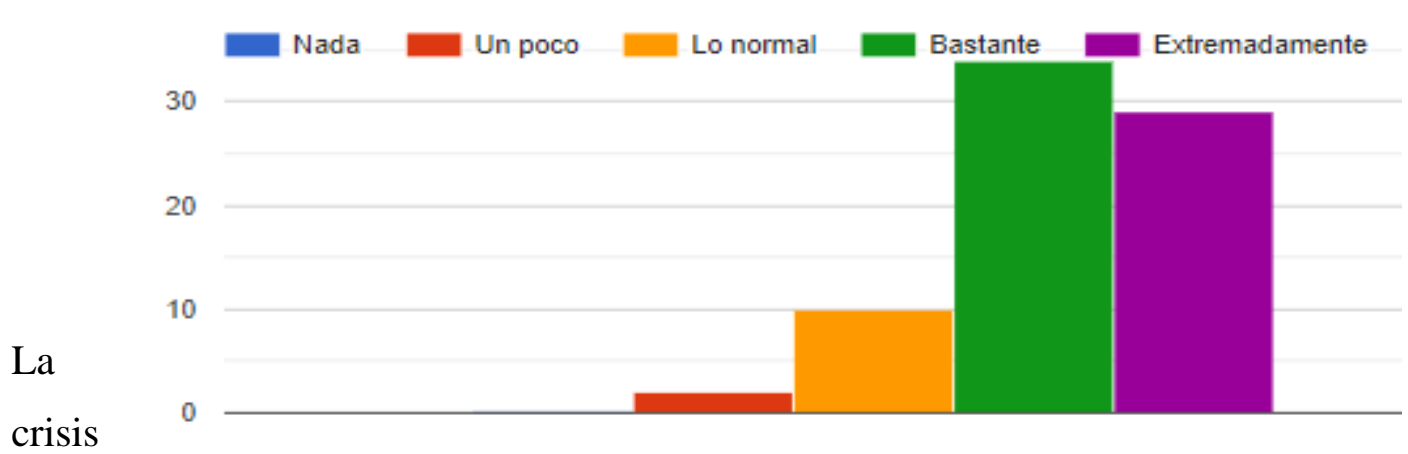

por la que atraviesa el mundo ha repercutido en los procesos regulatorios de las emociones y ha generado afectaciones a las personas, esta realidad puede que tenga su repercusión en el aprendizaje. El aislamiento social al que se han visto obligadas las personas, puede ser un factor que afecte a los estudiantes emocionalmente.

Sin embargo, la educación emocional no figura como un aspecto negativo en nuestra investigación, siendo que, de manera general los alumnos encuestados reflejan estabilidad emocional y sus relaciones personales, pese al confinamiento, han transcurrido de manera aceptable, en lo que indudablemente ha incidido la influencia del ambiente familiar y las condiciones de vida, lo que confirma los planteamientos realizados por autores tales como (Rieble-Aubourg y Viteri, 2020 y el Grupo del Banco Mundial, 2020), al referirse al impacto desigual que tiene el confinamiento, la enseñanza virtual, el acceso a los medios necesarios, en los estudiantes atendiendo a su condición o status social.

Se utilizó la plataforma de MAP Test para la obtención de datos cuantitativos, basados en las calificaciones obtenidas en el año lectivo 2019-2020, previo a la pandemia, y los resultados alcanzados en 2020-2021. Estos datos fueron analizados a través del programa informático estadístico SPSS, con el cual se pudo contrastar la curva de desarrollo de las destrezas adquiridas antes y durante la pandemia.

Los cuartiles inferiores color rosa y amarillo, marcan el crecimiento bajo de los estudiantes, en cuanto a destrezas y conocimientos para su grado o nivel, independientemente si son niños con determinado nivel de desarrollo de capacidades o con ciertas debilidades cognitivas. Los cuartiles superiores, naranja y verde, marcan un crecimiento alto de los alumnos, independientemente de que tengan un nivel alto o estándar de destrezas o no. Por esta razón, independientemente de las capacidades 
cognitivas de los alumnos, es posible evaluar si han desarrollado las destrezas necesarias en base a su edad y curso, o no.

En el año lectivo 2019-2020, pre confinamiento, se puede visualizar como se refleja en la gráfica que a continuación se presenta, una mayor cantidad de alumnos en los cuartiles inferiores, lo cual significa que estos no lograron el crecimiento esperado de acuerdo a su grado o edad; siendo así que un $44.71 \%$ de los alumnos evaluados no alcanzaron los resultados de haber desarrollado satisfactoriamente las destrezas para su nivel.

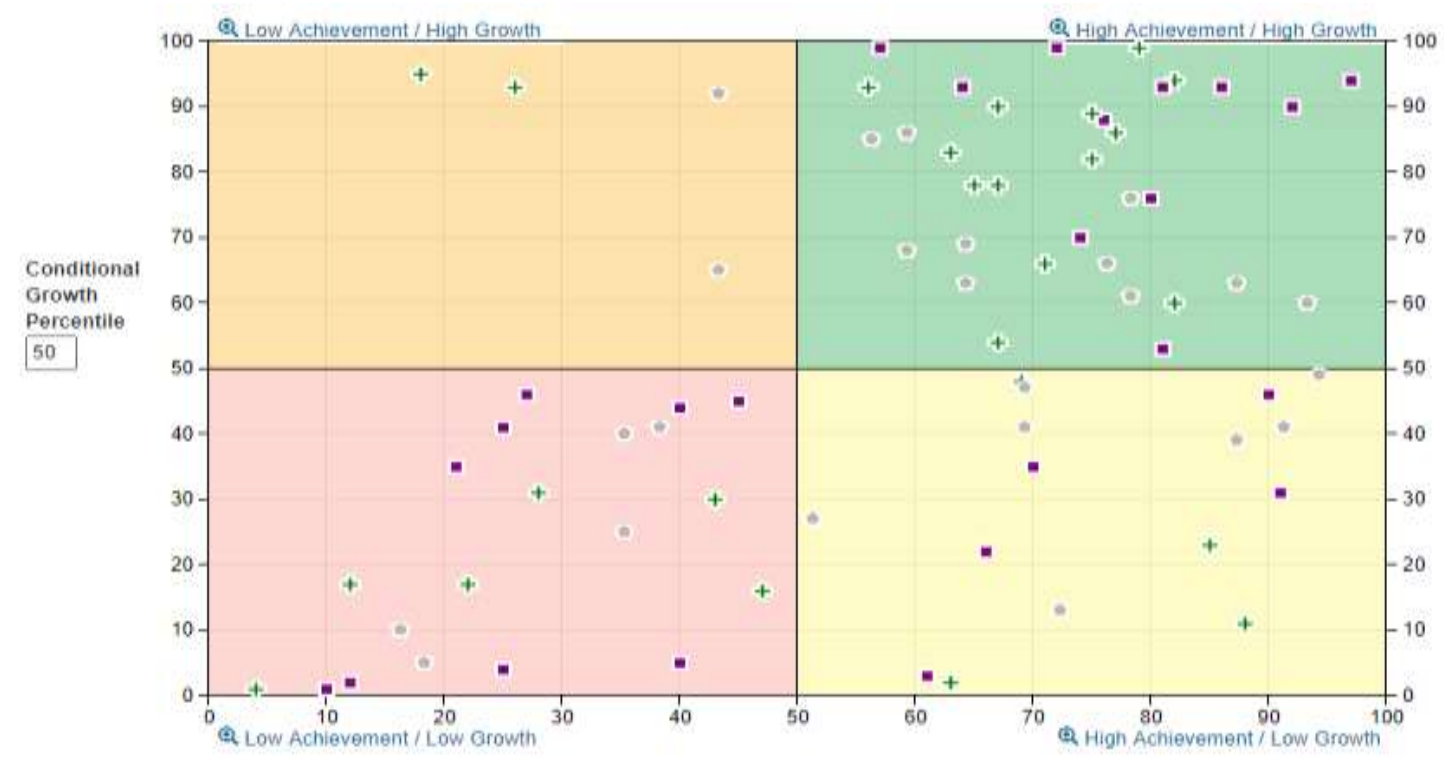

MAP TEST 2019-2020

\section{MAP TEST 2020-2021}

En la gráfica que representa el año lectivo 2020-2021, se aprecia un incremento de alumnos en los cuartiles superiores, lo cual se puede interpretar como un mayor crecimiento y mejores resultados de los alumnos de acuerdo con su grado o nivel. Siendo así que solo un $28.57 \%$ de los alumnos no lograron desarrollar las destrezas y alcanzar el rendimiento académico esperado de acuerdo a su edad y curso, durante el período de confinamiento. 


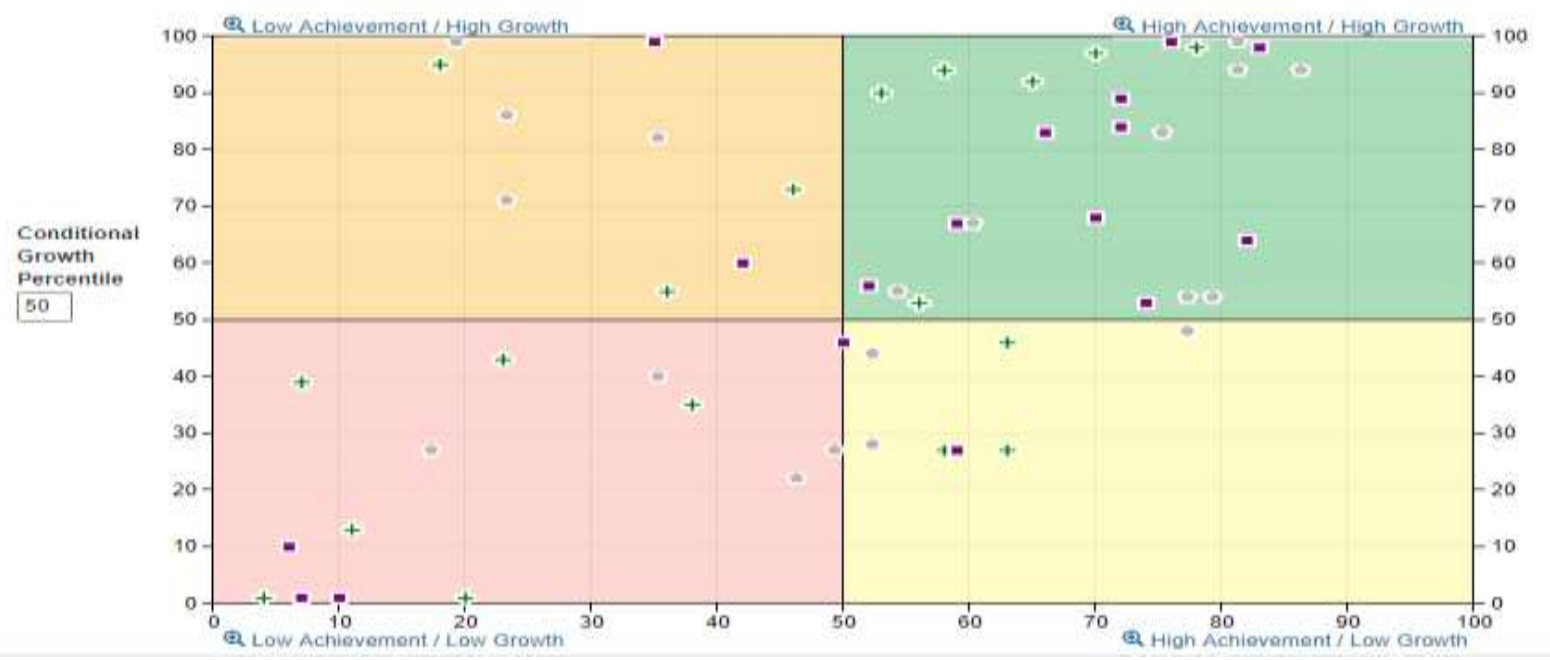

\section{CONCLUSIONES}

El contexto internacional por el que atraviesa la sociedad contemporánea provocado por la pandemia generada por el SARS-COV 2, ha traído cambios significativos en la vida de los seres humanos que han repercutido en todas las esferas de la vida social, la educación como una de ellas y la familia como núcleo fundamental de la sociedad, no han estado exentos de los embates que han producido dichos cambios.

El escenario educacional se trasladó a los hogares y los entornos virtuales sustituyeron las clases presenciales y por consiguiente el contacto directo entre docente y estudiantes, así como entre compañeros de grupo, lo que ha sido motivo de preocupación de decisores de políticas, familiares y académicos, por estas razones se han generado estudios que buscan profundizar en la realidad, identificar y explicar los fenómenos ocurridos y sugerir soluciones.

La presente investigación que se ha desarrollado buscando identificar el impacto del confinamiento generado por la COVID 19 en los procesos socioemocionales y de aprendizaje de los estudiantes de 7mo UBG del Colegio MENOR Campus Samborondón, y si bien es cierto que entre estos procesos existe una interrelación y el impacto puede ser negativo, se confirma que en estos estudiantes no ha existido una relación directa entre el período de confinamiento por la COVID 19 y determinados aspectos del desarrollo socioemocional y bajo rendimiento académico, por cuanto no se identifican alteraciones significativas en lo socioemocional y en el rendimiento académico alcanzado, pues este último es superior al período lectivo anterior al confinamiento. 
Los resultados alcanzados dada la población estudiada, reflejan la importancia e impacto del bienestar socio-emocional en relación con las condiciones de vida, la percepción de sí mismos, y la atención de la familia y amigos; así como otras condicionantes e incentivos que generaron un efecto positivo en los encuestados a pesar del confinamiento, como son la conexión con sus profesores en las clases virtuales, el desarrollo de la creatividad debido al drástico cambio de las clases presenciales a las virtuales, y el constante uso de aplicaciones y tecnología, lo cual ha resultado un estimulante en ellos por la significación que han tenido como medio de relación social.

Se considera la posibilidad de profundizar en investigaciones posteriores, utilizando poblaciones de diferente estrato social, sobre otros factores influyentes como pueden ser, la incidencia de la calidad de vida, el estatus social, la preparación y alcance para el uso de las tecnologías y las posibilidades de la familia para brindar apoyo, la motivación de los estudiantes, las necesidades de interacción entre compañeros, el uso de las clases virtuales como vía de conexión con otros pares y los docentes, el trabajo en equipo a través de plataformas virtuales, la creatividad generada para desarrollar los trabajos, como posibles justificantes de un incremento o descenso del rendimiento académico durante este período.

\section{REFERENCIAS BIBLIOGRÁFICAS}

Berger, C., Milicic, N., Alcalay, L., \& Torretti, A. (2014). Programa para el Bienestar y Aprendizaje Socioemocional en estudiantes de tercero y cuarto grado: descripción y evaluación de impacto Revista Latinoamericana de Psicología, 46(3), 169-177. (Recuperado de https://www.redalyc.org/pdf/805/80533065004.pdf

Bouzano-Poley E. (2003). El insomnio en la infancia. Revista de Neurología. Nº 36(4) pp. $\quad$ 381-390. DOI: https://doi.org/133/rn.3604.2002229

Blacutt, M. (2000) Estadística aplicada con SPSS (descriptiva inferencial), file:///C:/Users/ana-iris.perez/Downloads/Estadistica-Aplicada-con-Spss.pdf

CEPAL-UNESCO (2020) Informe Covid-19 La Educación en tiempos de pandemia de Covid19

(Recuperadodehttps://repositorio.cepal.org/bitstream/handle/11362/45904/1/S20 00510_es.pdf

Cohen, J. (2003). La inteligencia emocional en el aula: Proyectos, estrategias e ideas. Buenos 
Aires: Troquel.

García, A., Cuéllar, I. (2020) Impacto psicológico del confinamiento en la población infantil y como mitigar sus efectos: revisión rápida de la evidencia. Anales de Pediatría 2020;93(1): 57-58 DOI: 10.1016/j.anpedi.2020.04.015

Grupo Banco Mundial. Mayo 2020. Covid-19: Impacto en la educación y respuestas de política pública. Resumen Ejecutivo hedocs.worldbank.org/en/doc/1437715907569833430090022020/original/Covid19EducationSummaryesp.pdf

Hattie, J. (2015). Teacher-ready Research review. The applicability of visible learning to higher education. Scholarship of Teaching and Learning in Psychology, 2015, 1 (1),79-91. (Recuperado de: http://result.uit.no/basiskompetanse/wpcontent/uploads/sites/29/2016/07/Hattie.pdf. Citado por Esther Álvarez Bolaños.

Heredia, Y. (2020). El desarrollo emocional es tan importante como el académico. Observatorio Instituto para el futuro de la Educación. Instituto Tecnológico de Monterrey. (Recuperado de https://observatorio.tec.mx/edu-bitsblog/importancia-del-desarrollo-emocional-estudiantes

Heras, D., Cepa, A. Lara, F. (2016). Desarrollo emocional en la infancia. un estudio sobre las competencias emocionales de niños y niñas Revista INFAD de Psicología Vol. 1.n1.v1.217 pp.67-73 (Recuperado de https://revista.infad.eu/index.php/IJODAEP/article/view/217 https://doi.org/10.17060/ijodaep.2016

Hincapie, D., López, F. Rubio, M. (2020). El alto costo del COVID-19 para los niños. Estrategias para mitigar su impacto en América Latina y el Caribe. (junio 2020) file://CC:/Users/ana-iris.perez/Downloads/El-alto-costo-del-COVID-19-para-los-ninosEstrategias-para-mitigar-su-impacto-en-America-Latina-y-el-Caribe.pdf Intriago, M y Calle, R. (2021). Análisis psicosocial de la educación virtual en tiempos de pandemia, en estudiantes de básica superior. Pol. Con. (Edición núm. 54) Vol. 6, No 2 febrero 2021, pp. 618-640 ISSN: 2550 - 682X DOI: 10.23857/pc. v6i2.2293

Sabine, R., Viteri, A. Nota CIMA \# 20 COVID-19: ¿Estamos preparados para el aprendizaje en línea? Instituto Nacional de Evaluación Educativa need.edu.uy/nuestro-trabajo/recopilacion-de-trabajos-sobre-covid-19-y- 
educacion/550-nota-cima-20-covid-19-estamos-preparados-para-el-aprendizajeen-linea.html

Sánchez, A., Fuentes, V. (2020). COVID-19: cuarentena, aislamiento, distanciamiento social y confinamiento, ¿son lo mismo? Revista Anales de Pediatría Vol. 93 № 1 2020 ,

pp

DOI:10.1016/j.anpedi.2020.05.001https://www.analesdepediatria.org/es-covid19-cuarentena-aislamiento-distanciamiento-social-articulo-S1695403320301776

Torres, L., Rodríguez, N. (2006) Rendimiento académico y contexto familiar en estudiantes universitarios enseñanza e investigación en psicología vol. 11, $\mathrm{N}^{\circ} .2$ : $255-270$ julio-diciembre,2006 (Recuperado de https://www.researchgate.net/publication/26483544_Rendimiento_academico_y _contexto_familiar_en_estudiantes_universitarios 